\title{
Perspectives of Demand-Side Management in a Smart Metered Environment
}

\author{
A. Dán, D. Divényi, B. Hartmann, P. Kiss, D. Raisz and I. Vokony \\ Department of Electric Power Engineering \\ Budapest University of Technology and Economics \\ Egry Jozsef u. 18. V1 bdg. $2^{\text {nd }}$ floor, $\mathrm{H}-1111$ Budapest (Hungary) \\ Phone: +361463 3025, e-mail: dan.andras@vet.bme.hu, divenyi.daniel@vet.bme.hu, \\ hartmann.balint@vet.bme.hu, kiss.peter@vet.bme.hu, raisz.david@vet.bme.hu, vokony.istvan@vet.bme.hu
}

\begin{abstract}
Some distribution system operators (DSOs) - among them all Hungarian DSOs - have installed extensive demand-side management (DSM) infrastructure in order to be able to perform peak-clipping and valley-filling of the daily load curves. These systems rely either on the traditional ripple control (RC) or radio ripple control (RRC) technology. In this paper a short overview on the capabilities of these methods will be given, and compared to the DSM possibilities offered by Smart Metering (SM) based systems. In the focus of the paper a new modelling framework will be presented, which makes it possible to simulate the consumer behaviour on an appliance level in different DSM environments. The effects of direct DSM methods (like RC or RRC) and soft DSM (dynamic tariff systems) on the daily load curves will be analyzed in order to exploit the possibilities of SM systems.
\end{abstract}

\section{Keywords}

DSM, Smart Metering, Ripple Control, Radio Ripple Control, Consumer Behaviour Modelling, Household Appliance Models

\section{Introduction}

The power community is facing worldwide discussions about Smart Metering (SM) technology, the possible system structures and benefits to be expected from different SM systems. The 2006/32/EC directive prescribes the monthly reading and billing of the electric power consumption, this is why the different SM technologies are in use or under development (pilot projects) in several EU member countries.

This paper focuses on DSM issues and aims to contribute to SM systems design in the planning stage in order to enlarge the possibilities of a prospective metering infrastructure.

\section{RC and RRC}

\section{A. The application of RC in Hungary}

The Ripple Control system is a telegram based DSM system, where the carrier is the $50 \mathrm{~Hz}$ distribution network. In Hungary the application of the system has been started in 1975, basically for switching on and off boilers (electric storage water heaters) and high capacity storage space heaters. In the beginning of the 2000's the controlled power was approx. $1500 \mathrm{MW}$, which is one fourth of the winter peak load. [1], [2]

Applying RC system, hundred thousands of customers can be controlled from one place, as the sending device can be installed on any voltage level from LV to HV. The addressee can be either only one consumer, or a group of them. [3]

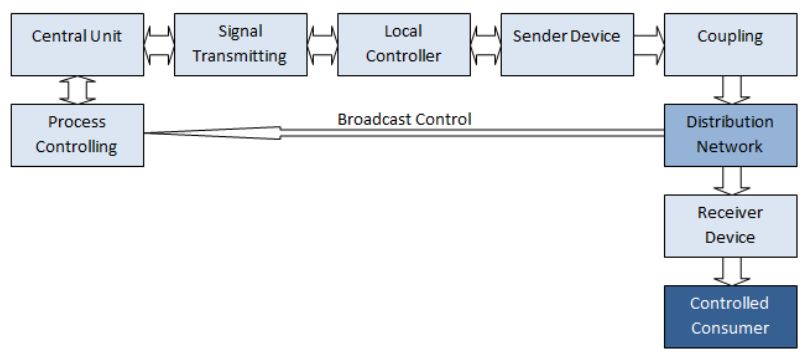

Fig. 1. The Ripple Control (RC) system

The simple structure (Fig. 1) could incur some possible problems, which are disadvantageous: [3]

- One-way communication: the DSOs do not have any reply from the addressees whether they received the message and fulfil the switching order or not?

- The distribution system is planned to transmit $50 \mathrm{~Hz}$ waveform: the transmission of other frequency components is not ideal.

Nowadays the RC system is used for the following purposes in Hungary: [3]

- Basic controlling:

○ Tariff shift

- Public lighting

- Customer's load controlling:

○ Boilers

- Electric storage space heaters

- Air conditioners

- Other controlling purposes:

- Civil defence siren

$\circ$ Factory switching

$\circ \quad$ Building and advertisement lights

The control is based on sending standardized telegrams. The task of the Sender Device is to generate the message 
with the proper power and voltage to reach all (including the furthest) controlled customers. The main parameters are given in Table I.: [2], [3]

Table I. - The RC Sender Device parameters

\begin{tabular}{|l|l|}
\hline Input Voltage & $0,4 \mathrm{kV}$ \\
\hline Nominal Power & $400 \mathrm{kVA}$ \\
\hline Modulation Frequency & $216.7 \mathrm{~Hz}$ and/or $183.3 \mathrm{~Hz}$ \\
\hline
\end{tabular}

Defining the modulation frequency some aspects should be considered: [2], [3]

- avoid frequencies near to whole number multiples of the $50 \mathrm{~Hz}$ fundamental frequency.

- keep the modulation frequency as low as possible.

\section{B. The application of RRC in Hungary}

There are some new demands that cannot be realized using the traditional RC system. In the beginning of 1990's the Radio Ripple Control (RRC) has been started to realize. Its structure can be studied on Fig. 2. [3], [4]

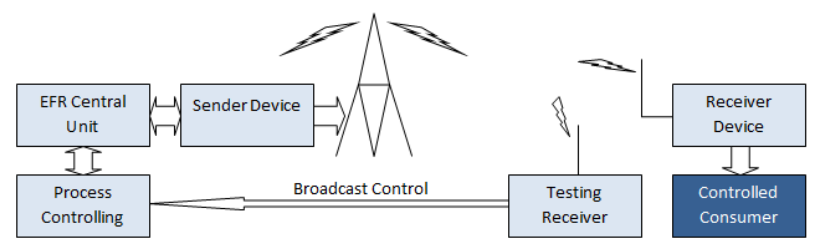

Fig. 2. The Radio Ripple Control (RRC) system

The novelty of RRC (compared with RC): [3]

- The messages are transmitted with long-wave antenna, thus the transmitting is independent from the topology of the electric network.

- The addressing interval is much wider, it is possible to address millions of consumers with one telegraph, thus it is enough to have one controlling frequency.

- It is possible to transmit messages to hundreds of kilometres, in some seconds

- The small gas motors and gas turbines are not affected.

The RRC operator in Central Europe is the Europäische Funk-Rundsteuerung GmbH (EFR), housed in Munich, Germany. The first RRC service was started in 1995. With three long-wave antennas they can cover Germany, Belgium, The Netherlands, Switzerland, Austria, Czech Republic, Slovakia, Hungary, Slovenia, and the rest of Croatia with the total transmitting power of $250 \mathrm{~kW}$. [3], [4]

The first two antennas are in Germany and working since 1995, the third one is standing in Hungary at Lakihegy (near Budapest) and started operating for the purposes of $\mathrm{RRC}$ in 2005. The main parameters are given in Table II. [4]
Table II. - The RRC long-wave antenna parameters [6]

\begin{tabular}{|l|c|c|c|}
\hline Antenna & Mainflingen & Burg & Lakihegy \\
\hline Starting operation & 1995 & 1995 & 2005 \\
\hline Height & $200 \mathrm{~m}$ & $315 \mathrm{~m}$ & $314 \mathrm{~m}$ \\
\hline Type & Vertical & $\begin{array}{c}\text { Double } \\
\text { cone }\end{array}$ & Double cone \\
\hline $\begin{array}{l}\text { Transmitting } \\
\text { power }\end{array}$ & $100 \mathrm{~kW}$ & $50 \mathrm{~kW}$ & $100 \mathrm{~kW}$ \\
\hline Carrier frequency & $129.1 \mathrm{kHz}$ & $\begin{array}{c}139.0 \\
\mathrm{kHz}\end{array}$ & $135.6 \mathrm{kHz}$ \\
\hline Modulation & FSK (Frequency Shift Keying) \\
\hline Frequency swing & \multicolumn{3}{|c|}{ $\pm 170 \mathrm{~Hz}$} \\
\hline Telegram speed & \multicolumn{3}{|c|}{$200 \mathrm{Bd}$} \\
\hline
\end{tabular}

\section{Smart Metering}

Different technologies can be addressed by the term "Smart Metering" (SM). Though more and more countries are discussing the application of a SM system, the experiences are limited and there are only few places, where the total meter roll-out has been finished. Most of the countries are still planning or running a pilot project to get more results. After the first experiences (Italy) it is possible to conclude that the application of SM should be preceded by more $R \& D$.

One of the best example are nowadays The Netherlands: the documentation of its complex SM tender is studied by several countries and referred to in the international literature. After the order of the Ministry of Economics, The Dutch Standard Institution has prepared the minimal standards for the application of Smart Meters. This is the often referred NTA 8130 (Netherlands Technical Agreement) document. The following requirements were defined: [6]

- regular and occasional meter reading by remote commands: this means the reading of the actual consumption values with time stamps, developing the administrative services;

- let the DSO promote energywise or energy conscious consumers;

- $\quad$ switching on and off electricity and gas smart meters by remote commands - individually or in groups;

- limiting of maximal load - individually or in groups;

- let the Suppliers (both electricity and gas suppliers) apply time differed tariff systems;

- $\quad$ support prepaid systems;

- support the monitoring of the distribution system.

The structure of the system can be seen on Fig. 3. The metering installation has the following communication ports: [6]

- P0: for communication with external devices (e.g. hand-held terminal) during installation and on-site maintenance of the metering installation.

- P1: for the communication between the metering installation and auxiliary equipment (a maximum of 5 appliances can be connected). P1 is a read-only interface, i.e. it cannot be used for sending data to the metering system. 
- $\quad$ P2: for the communication between the metering system and one-to-four metering instruments and/or grid company equipment.

- P3: for the communication between the metering installation and the Central Access Server (CAS). Important to note that the P3 interface will be based on the international DLMS/COSEM standard.

- P4 is the port on the CAS with which independent service providers, suppliers and grid companies gain access to the CAS.

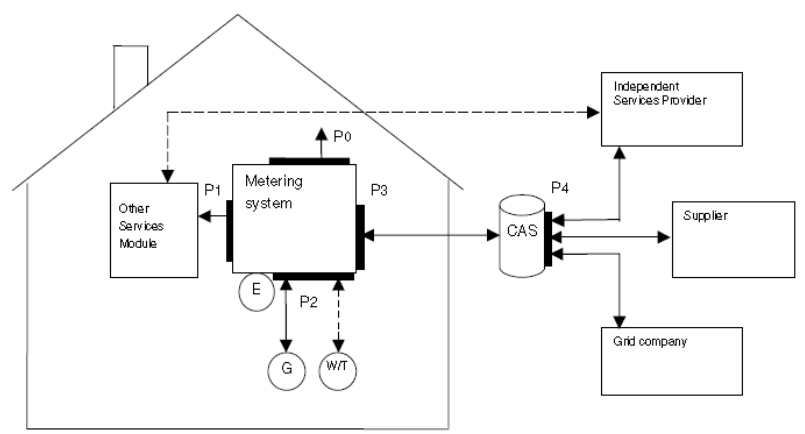

Fig. 3. The Smart Metering (SM) system [6]

The SM network is divided into four parts:

The smart meter is on the lowest level. Its task is the accurate measuring of the consumer's load.

The information of one group of smart meters is collected by a data concentrator. Its task is to communicate with the subordinated meters and to temporarily store the measured data.

The Central Access Server is on the top level. This is the place where the measured data is analysed and stored.

The fourth level is the transport layer between the elements, it can be both wired or wireless.

\section{A. The different Smart Metering systems}

1) AMR - Automatic Meter Reading: This is the base level of SM, where the task is only the automatic reading, collecting and storing the measured values. The main advantages of these systems are - compared to the traditional systems - that no human resources are needed for collecting the consumption values and the meter reading can be performed in an exact time point.

2) AMM - Automatic/Advanced Meter Management: This is an AMR based technology with bidirectional communication. (This feature is commonly understood as necessary to make meters really "smart".) Applying AMM more data can be stored in the meter (e.g. daily consumption curve, some information about the power quality, the meter's battery level) and some management possibilities can be applied. With an AMM system demand response actions (load switching) can be performed, e.g. for the purpose of smoothing the fluctuation of the daily load curve.

3) AMI - Advanced Metering Infrastructure: Well developed infrastructure is needed for the appropriate operation of AMM. This is the so called AMI. The AMI can be divided into three well-defined parts: the customers' devices (CD), the suppliers' devices (SD) and the information technology (IT) background. The CDs are the load monitoring and controlling devices, such as in-home displays (showing the actual consumption and other stored or received information) and load controller (which can e.g. switch off air conditioner when the price of electricity is high or shift the operation of a washing machine to night hours when the power can be bought at the lowest price). All the controlled devices that are included in DSM can be part of this group. The SDs are the elements of the metering network. The IT background contains software solutions for monitoring, billing and demand response supervision, as well as other services offered by the DSO.

\section{B. Smart metering and DSM}

If the SM systems are studied from the DSM point of view, three different solutions can be discussed:

1) There is no direct DSO-control over the customer's appliances. The customer is incited by previously defined or real-time tariffs. (The actual price can be shown on the display of the SM.) The switching or shifting of appliances depends on the customer's decision.

2) Still there is no direct DSO-control, but the customer uses a load controlling device. With this device the daily load curve can be optimized and the daily energy costs can be reduced. The control parameters (e.g. the washing machine should start working at an optimal price) can be adjusted by the customer.

3) The third version is when direct DSO-control is applied using the infrastructure of the SM system.

\section{Different DSM applications}

Several goals can be set when the DSM is in focus, e.g.:

- daily load curve shaping

- load limitation at system breakdowns

- minimizing of balancing energy (i.e. the minimization of the deviation of the actual load from the schedule) [9]

From the point of view of these goals it is important that a switching operation results in a change of active power consumption. This can be obstructed by the (illegal) usage of devices that switch the controlled appliances from the controlled line to the uncontrolled line and back for the sake of continuous supply and cost reduction. One field of research (not detailed in this paper) could be the detection of the usage of such devices.

To minimize the balancing energy very accurate load profiles should be known. Another field of research underway is the accurate estimation of the actual load based on SM readings. 


\section{Modelling of Consumer Behaviour}

The central topic of the paper, namely a new stochastic consumer behaviour modelling framework will be presented in this chapter.

\section{A. Appliances}

Household consumers use different appliances, which will be divided into three groups based on their usage: [7]-[9]

1) Controllable appliances. The first group consists of appliances that are good candidates for being controlled by the DSO; these devices most frequently comprise some storage behaviour (mainly thermostatically controlled appliances like storage water heaters, airconditioners, deep freezers), but also washing machines or dishwashers can be members of this group; these devices will be called "controllable appliances". The implemented appliances can be studied in Table III. The models are based on differential equations, taking into account their previous usage and thermal behaviour. [10]

Table III. - The modelled controllable appliances

\begin{tabular}{|l|l|l|l|}
\hline Appliance & Power & Incidence & $\begin{array}{l}\text { Comfort } \\
\text { limit }\end{array}$ \\
\hline boiler & $1800 \mathrm{~W}$ & $39 \%$ & $\mathrm{~T}>72^{\circ} \mathrm{C}$ \\
\hline air-conditioner & $670 \mathrm{~W}$ & $10 \%$ & $\mathrm{~T}<22^{\circ} \mathrm{C}$ \\
\hline deep freezer & $360 \mathrm{~W}$ & $77 \%$ & $\mathrm{~T}<-12{ }^{\circ} \mathrm{C}$ \\
\hline
\end{tabular}

2) Reschedulable appliances. The second group will be called "reschedulable appliances", because their usage time is assumed to be changed (compared to the "normal" usage time) by consumers if motivated by the actual electricity prices. The parameters of these appliances can be studied in Table IV. The values define the switching probabilities (see "daily switching rate") and the average daily operational times.

Table IV. - The modelled reschedulable appliances

\begin{tabular}{|c|c|c|c|c|}
\hline Appliance & Power & $\begin{array}{c}\text { Daily } \\
\text { switching } \\
\text { rate }\end{array}$ & Op. time & Incidence \\
\hline $\begin{array}{c}\text { washing } \\
\text { machine }\end{array}$ & $1000 \mathrm{~W}$ & 0.35 & $64 \mathrm{~min}$ & $72 \%$ \\
\hline dish-washer & $900 \mathrm{~W}$ & 0.60 & $61 \mathrm{~min}$ & $14 \%$ \\
\hline $\begin{array}{c}\text { vacuum- } \\
\text { cleaner }\end{array}$ & $1200 \mathrm{~W}$ & 0.20 & $21 \mathrm{~min}$ & $95 \%$ \\
\hline water heater & $2000 \mathrm{~W}$ & 0.16 & $20 \mathrm{~min}$ & $50 \%$ \\
\hline el. oven & $3500 \mathrm{~W}$ & 0.15 & $80 \mathrm{~min}$ & $10 \%$ \\
\hline
\end{tabular}

The time of day when a device is switched on is determined based on cumulative distribution functions that can be derived from measurement results presented in [8].

3) Other appliances. The last group consists of all other appliances, which are thus assumed to be inaccessible by any DSM program, and are therefore not included in the models below.
Detailed models have been investigated using MATLAB for the controllable and the reschedulable appliances. During the calculations it is assumed that the appliances operate at their nominal power. Considering only one appliance this is certainly not true, but because the total power of a group of appliances is computed, the above approximation is reasonable.

\section{B. Customers}

A methodology has been elaborated to model the customer behaviour in case of a dynamic pricing environment, where different consumers choose to reschedule their respective appliances depending not only on the prices but also on their attitude towards saving on their electricity bill.

\section{1) Model of Rescheduling Propensity}

This customer behaviour model will be used for the reschedulable appliances.

The Rescheduling Propensity of the customers can be derived from an economical point of view. The rational customer's goal is to minimize the total cost, including two components:

- operational cost: the cost paid after the energy consumption of the appliance;

- fictive cost: if the customer decides to "reschedule" the usage of an appliance (i.e. it is not working in its "normal" usage time), he has to tolerate some discomfort, which can be represented by this fictive additional cost.

Both parts are depending on the time of switching on. If the consumer has higher energy cost saving during a reduced price period than the fictive cost (which is associated with rescheduling the appliance from the normal usage time), his total cost is lower thus he will reschedule the appliance.

The fictive cost can be calculated using the following equation:

where

$$
c_{\text {fictive }}=c_{\text {pre }} \cdot c_{\text {app }} \cdot c_{\text {cons }} \cdot|\Delta t|
$$

$|\Delta t| \quad$ the time shift $(h)$;

$\boldsymbol{c}_{\text {cons }}$ consumer-dependent factor that follows a normal distribution; it represents the fraction of the operational cost expected to be saved due to a one-hour rescheduling. In the simulations its expected value was set to $0.1\left(h^{-1}\right)$

$\boldsymbol{c}_{\boldsymbol{a p p}}$ appliance-dependent reschedulability factor, see values in Table $\mathrm{V}$;

$\boldsymbol{c}_{\text {pre }}$ human behaviour which represents that people prefer positive time shift over negative (i.e. they postpone an activity rather than antedate it).

Table V. - The reschedulability factor of the appliances

\begin{tabular}{|l|l|}
\hline Device & $\mathbf{c}_{\text {app }}$ \\
\hline washing machine & 1.2 \\
\hline dish-washer & 0.5 \\
\hline vacuum-cleaner & 0.5 \\
\hline water heater & 0.5 \\
\hline el. oven & 0.8 \\
\hline
\end{tabular}




\section{2) Modelling Switching Off Propensity}

This model will be used for controllable appliances in cases when no direct load control is applied, but the customer responds to intra-day tariff changes (see cases 1 and 2 in paragraph $B$. of Chapter 3 ). The assumed intervention of the customer is limited to switching off the appliance; switching on is determined by the thermostat if the appliance is not turned off.

The propensity of turning off an appliance depends on some parameters related to the comfort level of a customer. In Table III the so called comfort limits can be seen. E.g. if the temperature inside a deep freezer does not exceed $-12^{\circ} \mathrm{C}$, the consumer's comfort is not violated. The switching off procedure can be studied on Fig. 4. The consequences of the possibility of switching off an appliance are analysed from time to time (the period should be fixed between 5 to 30 minutes; the simulations in this paper have been run with a period of 30 minutes). If the switching off command would cause deficit or some of the comfort parameters would violate the limits (see Table III.) the command will not be issued. In all other cases, the switching off command will be active.

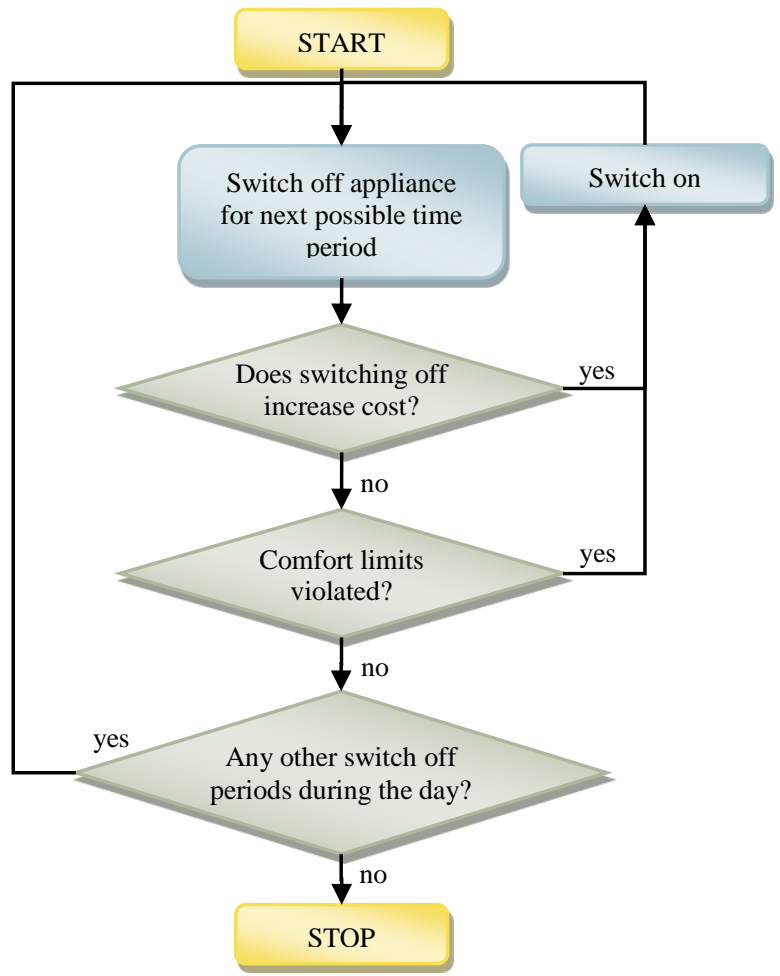

Fig. 4. The algorithm of switching off an appliance

The algorithm should be run for every fixed time period during the day. The results of the algorithm are time instances at which a customer switches off its appliances.

It is important to notice, that in case of switching off an appliance the saved energy and cost cannot be calculated using only the average power of that appliance. This is due to the well-known payback effect of certain appliances (i.e. the deferred energy will be consumed later). Cost saving can be achieved by rescheduling the consumption to a reduced tariff time period.

\section{Results}

In this chapter the simulation results will be shown based on a statistical evaluation of some thousand household consumption curves. The curves shown for each appliance represent the average of some thousand appliances, rated with the incidence of the appliance.

\section{A. Base case}

In this case we apply only one tariff which is timeinvariant. Its value was set to $49 \mathrm{HUF} / \mathrm{kWh}$ $(\approx 0,18 € / \mathrm{kWh})$, which was the normal tariff in 2010 in Hungary for household customers. The DSO does not apply any load control.

The daily consumption curves of the controllable and reschedulable appliances together with the actual tariff can be studied on Fig. 5 and Fig. 6. It can be concluded that the highest consumption belongs to the boiler and the air-conditioning has the smallest percentage. The daily consumption curve of households can be represented with a morning and evening peak period and a night-time deep valley period.

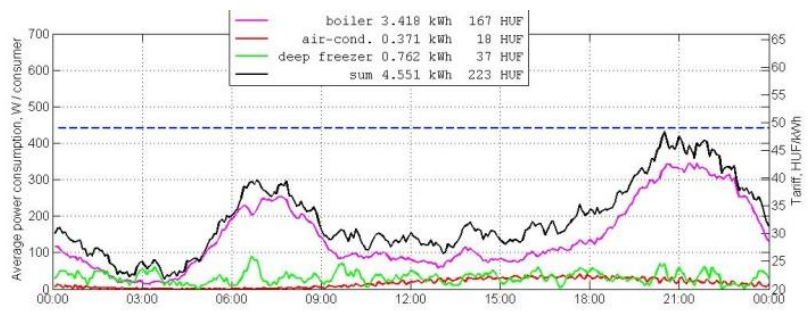

Fig. 5. Base case, controllable appliances

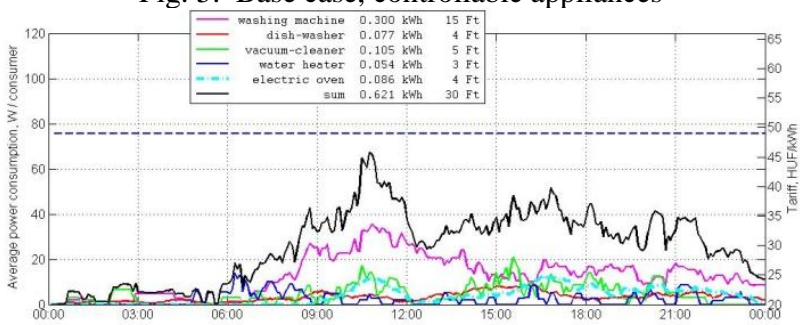

Fig. 6. Base case, reschedulable appliances

\section{B. Tariff based incentive}

In this case we are applying a hypothetic tariff system to stimulate the customers to avoid consuming during the morning and evening peak period. The tariff had been determined with the following criteria:

- if the customer does not apply rescheduling, the average cost will not change;

- if the customer is energywise, he can save on energy costs;

- $\quad$ the DSO does not apply direct load control.

The results can be studied in Table VI and on Figs. 7 and 8. It can be seen that although there is no significant difference in the daily energy consumption, the customers achieved $33 \mathrm{Ft}$ saving daily, which is $13.2 \%$ of the total energy cost of controlled and reschedulable consumers. 
Table VI. - The effect of the tariff incentive

\begin{tabular}{|l|l|l|l|l|l|l|}
\cline { 2 - 8 } \multicolumn{1}{c|}{} & \multicolumn{2}{c|}{ Base } & \multicolumn{2}{c|}{$\begin{array}{c}\text { Tariff } \\
\text { incentive }\end{array}$} & \multicolumn{2}{c|}{ Change } \\
\hline \multicolumn{1}{|c|}{ Appliance } & $\begin{array}{c}\mathbf{E} \\
\text { kWh }\end{array}$ & $\begin{array}{c}\mathbf{C} \\
\text { HUF }\end{array}$ & $\begin{array}{c}\mathbf{E} \\
\mathbf{k W h}\end{array}$ & $\begin{array}{c}\mathbf{C} \\
\mathbf{H U F}\end{array}$ & $\begin{array}{c}\mathbf{\Delta E} \\
\mathbf{\%}\end{array}$ & $\begin{array}{c}\mathbf{\Delta C} \\
\mathbf{\%}\end{array}$ \\
\hline boiler & 3.42 & 167 & 3.37 & 144 & -1.5 & -14.0 \\
\hline air-cond. & 0.37 & 18 & 0.34 & 16 & -9.2 & -12.0 \\
\hline deep freezer & 0.76 & 37 & 0.75 & 32 & -1.2 & -14.3 \\
\hline washing m. & 0.30 & 15 & 0.30 & 15 & 0.0 & 2 \\
\hline dish-washer & 0.08 & 4 & 0.08 & 3 & 0.0 & -20.5 \\
\hline vacuum-cl. & 0.11 & 5 & 0.11 & 4 & 0.0 & -22.3 \\
\hline water heater & 0.05 & 3 & 0.05 & 2 & 0.0 & -24.4 \\
\hline el. oven & 0.09 & 4 & 0.09 & 4 & 0.0 & -5.1 \\
\hline Sum & $\mathbf{5 . 1 7}$ & $\mathbf{2 5 3}$ & $\mathbf{5 . 0 8}$ & $\mathbf{2 2 0}$ & $\mathbf{- 1 . 8}$ & $\mathbf{- 1 3 . 2}$ \\
\hline
\end{tabular}

The morning and evening peak periods had been reduced, but large gradient changes in the total load can be observed. The reason is the behaviour of the rational customers: they would like to minimize the negative consequences of rescheduling, thus they switch on their reschedulable appliances immediately after the tariff gets lower.

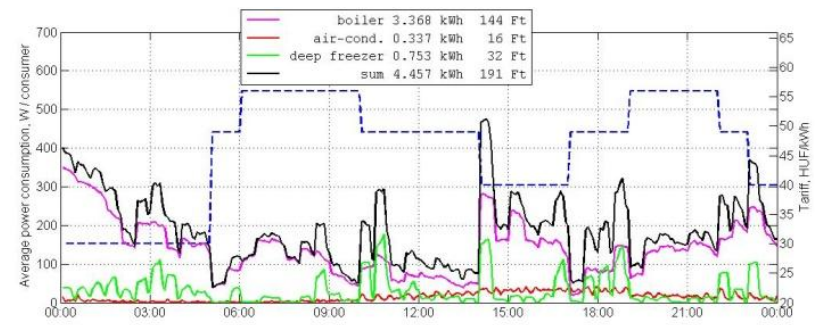

Fig. 7. Tariff incentive, controllable appliances

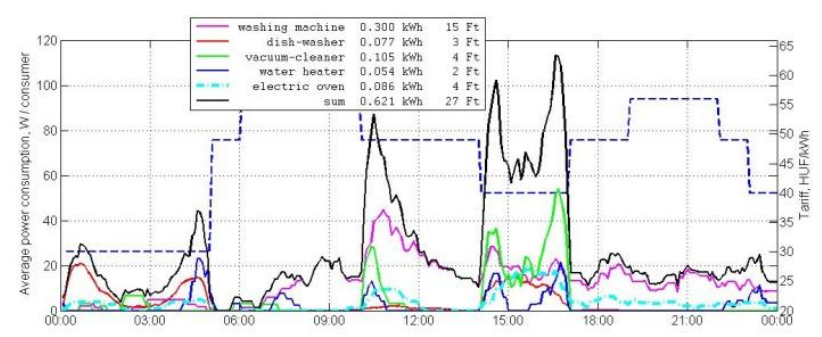

Fig. 8. Tariff incentive, reschedulable appliances

\section{Consumption with direct DSM}

In the final case the effect of direct DSM has been studied instead of customer rescheduling. The controlled tariff is $30 \mathrm{HUF} / \mathrm{kWh}(\approx 0,11 € / \mathrm{kWh})$, which was the reduced rate in 2010 .

The results can be studied on Fig. 9. The load redistribution is more significant than in the tariff incentive case. The steep load slopes can be reduced with DSM program optimization. It can be concluded that the comfort of the customers have not changed in case of boilers and deep freezers (the consumption values are nearly the same). The cost saving is much higher because the consumption is possible on a very low tariff. The consumption of the air-conditioners has been reduced dramatically, and in this case the comfort limits have been violated. Thus a special direct load control program is necessary for air-conditioners in order to keep the comfort level on an acceptable value.

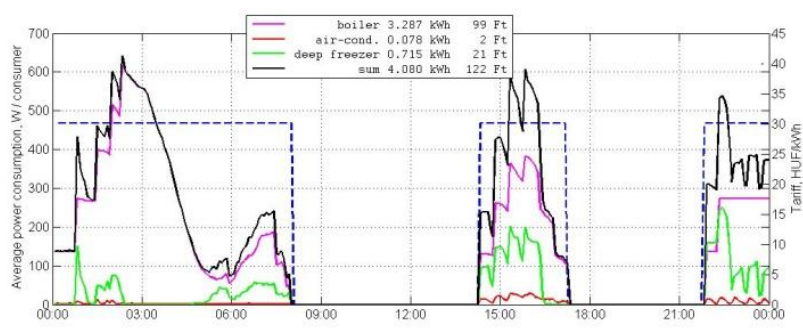

Fig. 9. Direct DSM, controllable appliances

\section{Conclusion}

In this paper a new model has been presented that is capable of simulating the effects of different DSM actions. It has been shown that the household customers can be incited with a dynamic tariff system in order to reschedule their electric devices. This will cause consumption redistribution from the peak load periods to the valley load period.

However in case of system breakdown a fast (but smart) load shedding can only be achieved with direct DSM. Thus the possibility of direct load control is essential and should be exploited in SM systems.

Another reason to apply direct load control is the need to avoid large gradient load changes observed when simulating customer response to tariff incentives.

It has also been demonstrated that load curve shaping can be performed more effectively if direct load control is applied for boilers and deep freezers - compared to the case when only a tariff incentive is applied. A special load control program is necessary for air-conditioners.

\section{References}

[1] K. Oswald, Gy. Nagy, and J. Vimi, Ripple Control System (Hangfrekvenciás központi vezérlés). Budapest (1981), Müszaki Könyvkiadó (book in Hungarian)

[2] László Németh, Ripple Control System in the Electric Power Distribution and Demand-Side Management (A hangfrekvenciás központi vezérlés a villamosenergia-ellátásban és távvezérlésben), Budapest (1993), OMIKK (book in Hungarian)

[3] B. Máthé, The Effect of Distributed Generation on the RC Signal, Diploma thesis, BUTE Department of Electric Power Engineering, Budapest (2004), (in Hungarian)

[4] Radio Causing Ripples, in Power Industry Development no. 1/2005, http://www.efr-funk.com/com/press/radio/index.htm

[5] How Radio Ripple Control Works, EFR Europäische FunkRundsteierung (2005), Technical report, http://www.efrfunk.com/com/download/pdfs/funkrundsteuerung.pdf

[6] KEMA Consulting, Main Document - Dutch Smart Meter Requirements, The Netherlands (2009).

[7] Central European University, Residential Monitoring to Decrease Energy Use and Carbon Emissions in Europe (REMODECE, 2006).

[8] ISR-University of Coimbra, Residential Monitoring to Decrease Energy Use and Carbon Emissions in Europe (REMODECE, 2008).

[9] Central Statistical Office, Expenses of Households related to Electricity, KSH, Budapest (in Hungarian)

[10] D. Raisz, A. Dán, „Modeling of Remote-Controlled Loads and Determination of their Switching Schedules", in Journal Elektrotechnika, Vol. 01/2009, pp. 5-8. (in Hungarian) 